\title{
BMJ Open Involvement of people with dementia in making decisions about their lives: a qualitative study that appraises shared decision-making concerning daycare
}

\author{
Leontine Groen-van de Ven, ${ }^{1}$ Carolien Smits, ${ }^{1}$ Fuusje de Graaff, ${ }^{2}$ Marijke Span, ${ }^{3}$ \\ Jan Eefsting, ${ }^{4}$ Jan Jukema, ${ }^{1}$ Myrra Vernooij-Dassen ${ }^{5}$
}

To cite: Groen-van de Ven L, Smits C, de Graaff F, et al. Involvement of people with dementia in making decisions about their lives: a qualitative study that appraises shared decision-making concerning daycare. BMJ Open 2017;0:e018337. doi:10.1136/ bmjopen-2017-018337

- Prepublication history for this paper is available online. To view these files, please visit the journal online (http://dx.doi. org/10.1136/bmjopen-2017018337).

Received 22 June 2017 Revised 14 August 2017 Accepted 25 August 2017

\section{CrossMark}

${ }^{1}$ Research Group Innovating with Older Adults, Windesheim University of Applied Sciences, Zwolle, The Netherlands ${ }^{2}$ MUTANT Agency for Diversity and Change, The Hague, The Netherlands

${ }^{3}$ ProMemo Expertise Centre for Professionals in Dementia Care, WindesheimUniversity of Applied Sciences, Zwolle, The Netherlands

${ }^{4}$ Department of Nursing Home Medicine, VU University Medical Centre, Amsterdam, The Netherlands

${ }^{5}$ Radboud University Nijmegen Medical Centre, Scientific Institute for Quality of Healthcare and Nijmegen Alzheimer Centre, Nijmegen, The Netherlands

Correspondence to Leontine Groen-van de Ven; Im.groen-vande.ven@ windesheim.nl

\section{ABSTRACT}

Objective To explore how people with dementia, their informal caregivers and their professionals participate in decision making about daycare and to develop a typology of participation trajectories.

Design A qualitative study with a prospective, multiperspective design, based on 244 semistructured interviews, conducted during three interview rounds over the course of a year. Analysis was by means of content analysis and typology construction.

Setting Community settings and nursing homes in the Netherlands.

Participants 19 people with dementia, 36 of their informal caregivers and 38 of their professionals (including nurses, daycare employees and case managers).

Results The participants' responses related to three critical points in the decision-making trajectory about daycare: (1) the initial positive or negative expectations of daycare; (2) negotiation about trying out daycare by promoting, resisting or attuning to others; and (3) trying daycare, which resulted in positive or negative reactions from people with dementia and led to a decision. The ways in which care networks proceeded through these three critical points resulted in a typology of participation trajectories, including (1) working together positively toward daycare, (2) bringing conflicting perspectives together toward trying daycare and (3) not reaching commitment to try daycare.

Conclusion Shared decision making with people with dementia is possible and requires and adapted process of decision making. Our results show that initial preferences based on information alone may change when people with dementia experience daycare. It is important to have a try-out period so that people with dementia can experience daycare without having to decide whether to continue it. Whereas shared decision making in general aims at moving from initial preferences to informed preferences, professionals should focus more on moving from initial preferences to experienced preferences for people with dementia. Professionals can play a crucial role in facilitating the possibilities for a try-out period.
Strengths and limitations of this study

- This study is based on rich interview data collected in three rounds from care networks consisting of multiple participants: people with dementia, their informal caregivers and their professionals.

- The perspectives of people with dementia themselves are often neglected in research.

- Data were collected by various interviewers, some of whom were undergraduate students. All the interviewers were trained and received feedback on their interview style after each interview, but there were still differences in the extent to which they persisted in asking questions.

- We made sure that the interviews of each care network in a given interview round were conducted by one interviewer.

- This study involves people with dementia who were able to participate in an interview and who had informal caregivers present. Cases in which the person with dementia cannot communicate and cases in which no informal caregivers are present would likely present different or additional experiences.

\section{INTRODUCTION}

Daycare is an important source of support for people with dementia who want to live at home for as long as possible. ${ }^{12}$ It is a regular form of care for community-dwelling people with dementia in various countries worldwide. ${ }^{1-5}$ It aims to stimulate the person with dementia and relieve the burden on caregivers. ${ }^{45}$ As such, daycare may be helpful in delaying institutionalisation. Deciding about daycare may be complex, since it is often the first source of support outside the home-a time when people with dementia and their caregivers are not yet used to discussing support options with professionals. The subject of daycare arises when people with dementia increasingly have to rely on others to complete cognitive tasks, have difficulties 
with structuring the day, but are still aware of and able to express their wishes. ${ }^{2}$ It is often a time when care becomes burdensome for informal caregivers. It is important to involve people with dementia in these decisions, since involvement contributes to the well-being and quality of life of both the people with dementia and their informal caregivers. $^{67}$

Shared decision making is the preferred way of reaching decisions with patients. ${ }^{8-10}$ It is a method whereby professionals help patients choose healthcare options by exchanging information and evidence about options, as well as discussing the patient's values in order to elicit his or her preferences. However, although shared decision making is recommended, it is not common practice yet in dementia care. ${ }^{11}$ Decision making in the context of dementia is complex, dynamic, time consuming and full of emotions. ${ }^{12}$ Complex decision-making situations are characterised by insufficient clinical evidence, lack of clearly defined goals and options, and preferences that are contextual, provisional and conditional. ${ }^{13}$ In dementia care networks, multiple participants contribute to decision making over long periods of time. Professionals who facilitate shared decision making must therefore combine all the participants' perspectives. Moreover, shared decision making in dementia care networks may be challenged by tensions in the interactions between the participants and the need to adapt to the diminishing independence of the person with dementia. ${ }^{14}$

Diminishing independence also influences the roles of people with dementias in the decision making. Decision making is often described as a solely cognitive task, which makes it difficult for people with dementia. ${ }^{15}$ However, research has pointed out that they are able to state consistent choices and preferences. ${ }^{16-18}$ Moreover, decision making involves more than mere analytical thinking, since preferences and their underlying care values are also shaped by emotions and social interactions. ${ }^{19-21}$ Emotions and social interactions continue to be present during the course of the dementia trajectory, making it possible to include people with dementia even when the dementia progresses. For instance, informal caregivers and people with dementia deciding together give patients a chance to maintain a role in decision making by using their extant capacities. ${ }^{22} 23$ Professionals who want to involve people with dementia in decision making should also encourage informal caregivers to play a role. However, the informal caregivers have their own interests in the decisions, which means that shared decision making includes weighing up the different perspectives and interests present. ${ }^{14}$ In addition, informal caregivers can influence the level of involvement of the person with dementia on the basis of their own judgements of the person's decision-making capacities. ${ }^{22-24}$ This takes place at the risk of marginalising the person with dementia. ${ }^{22-24}$ Professionals are challenged to involve informal caregivers in decision making, elicit their perspectives and interests and, at the same time, take the preferences of persons with dementia into account. There is a lack of evidence about how people with dementia, their informal caregivers and their professionals participate in the different stages of the decision making. The decision about daycare is of particular interest because it is a complex decision where the interests of both the person with dementia and the informal caregivers are at stake.

This study had two objectives: first, to explore how people with dementia, their informal caregivers and their professionals participate in decision making about daycare and, second, to develop a typology of participation trajectories to get a clearer understanding about the way care networks proceed through the decision making process collaboratively. This information is for professionals who support people with dementia and their informal caregivers in making decisions about health and well-being. Furthermore, the results of this study add to the debate on social health and citizenship of people with dementia and help move forward the shared decision-making research about people with dementia.

\section{METHODS \\ Design}

We used a qualitative, prospective, multiperspective design to gain in-depth insight into the experiences of participating in decision making about daycare from the perspectives of people with dementia, their informal caregivers and their professionals. The participants were interviewed three times over the course of a year. This study is part of a research programme about shared decision making in dementia care networks. ${ }^{25}$

\section{Setting}

This study included community-living and institutionalised people with dementia in the Netherlands in the early and moderate stages of dementia who made a decision about daycare in the Netherlands. Daycare is a common form of support for community living people with dementia. However, several institutions in the Netherlands provide daycare services for institutionalised people with dementia as part of their daily support. Our participants included mainly community living people with dementia as well as several people with dementia who lived in institutions.

\section{Participants}

We purposively selected care networks of people with dementia: networks consisting of a person with dementia, two of his or her informal caregivers and two professional caregivers. ${ }^{26}$ We aimed for maximum variation regarding the characteristics of the person with dementia (gender, socioeconomic status and stage of dementia) and the types of informal caregivers (spouses, adult children, other relatives and friends). We used three recruitment routes: (1) healthcare organisations for people with dementia, (2) a local meeting for informal caregivers and people with dementia, and (3) the website of the Dutch Alzheimer's Society. The inclusion criteria were a diagnosis of 
any form of dementia, the ability to participate in an interview and the availability of at least one informal caregiver. The exclusion criteria were no confirmed diagnosis of dementia and the inability of the person with dementia to participate in an interview. We aimed to include 20-30 care networks in order to reach data saturation. ${ }^{27}$

\section{Data collection}

We interviewed the individual participants of the care networks at 6-month intervals, between July 2010 and July 2012. Twenty-two interviewers had been trained to conduct the semistructured interviews using an interview guide. The interviewers included three researchers from the research team (LG, MS and another researcher) and students studying for bachelor degrees (in nursing, speech therapy or applied gerontology). The researchers (LG and MS) trained the students in qualitative interviewing and interviewing people with dementia. The same interviewer interviewed all the care network members in a given interview round. The interviews lasted 1 hour on average, and they were audiotaped. The interview guides for the three rounds contained similar topics: the changes that had occurred, the decisions that were made, what had happened before these decisions, who was involved and how people had experienced the decision making. Interviews were conducted at the home or workplace of the respondent. We stressed the importance of interviewing the participants alone to avoid influence from others. ${ }^{28}$ However, in three care networks, the person with dementia was willing to participate only in the presence of the informal caregiver.

\section{Data analysis}

The interviews were transcribed verbatim and analysed with Atlas.ti software. To reach our two study objectives, we used a two-step approach that combined a content analysis ${ }^{29}$ with a methodology of type construction. ${ }^{30} \mathrm{We}$ used constant comparison in both steps. ${ }^{31}$

\section{Step 1: Content analysis (objective 1)}

The content analysis aimed at developing categories and themes related to the participation of people with dementia, their informal caregivers and their professionals in the decision making about daycare. This started with open coding of the individual interviews of each care network in the three interview rounds, which meant reading the interview transcripts and labelling the relevant fragments. Codes were thus constructed on the basis of the information of the individual perspectives in each care network and the three interview rounds. ${ }^{32}{ }^{33}$ Coding was done by two researchers independently (LG and $\mathrm{FdG}$ ) who agreed on the final code list. After the open coding, we developed categories and themes by grouping codes into meaningful clusters related to the participation in the decision making about daycare. ${ }^{31}$

\section{Step 2: Typology construction (objective 2)}

To develop our typology of the participation trajectories, we used a method for developing empirically grounded typologies, which consists of the following components ${ }^{30}$ : (1) development of the relevant analysing dimensions and properties, (2) grouping the cases and analysis of the empirical regularities, (3) analysis of meaningful relationships and type construction and (4) characterisation of the constructed types. For the first component, we developed our dimensions and properties from the themes and categories elicited in the content analysis in step 1. For the second component, we made matrices displaying the dimensions and properties for each member of a care network. For the third component, we made comparisons within and between the care networks to construct the types. Since our focus was on how care networks proceeded through the decision-making process collaboratively, our typology was based on the differences in the combination of the properties of different care network members within each care network. Thus, by comparing within and between care networks, we were able to group care networks that had similar combinations of properties between the care network members. This resulted in three types of participation trajectories that were then described on the basis of their properties (component 4). LG prepared the components of the typology construction and discussed these with her supervisors (MV and CS) which led to the final version of the typology.

\section{Constant comparison}

Constant comparison was at the heart of our qualitative analysis in all steps. Constant comparison implies comparing newly analysed data with emerging ideas about the research question. ${ }^{31}$ In our analysis, we used comparisons at different levels: within individual interviews, between individual interviews within a care network, between interviews of different types of respondents, between interview rounds for a given care network and between care networks. ${ }^{34}$

\section{Ethical considerations}

Respondents received written information about the study beforehand. Because of the vulnerability of people with dementia as research subjects, participation in the study required the consent of both the person with dementia and his or her primary informal caregiver. We treated the participants' consent, especially that of the people with dementia, as a process, ${ }^{35}$ and remained alert to signs indicating that the participant wanted to stop the interview. ${ }^{36}$ We did not share interview information with other network participants. ${ }^{32}$ This study was supported by the Regional Attention and Action for Knowledge Circulation programme of the Foundation Innovation Alliance (SIA-Stichting Innovatie Alliantie) with funding from the Ministry of Education, Culture, and Science (project number PRO-1-014). The funder had no role in the study design, data collection, analyses and interpretation of the data or in the writing of the article or the decision to submit it for publication. All researchers had access to all the data. 


\section{Patient involvement}

The research question was developed after consulting professionals in dementia care, as well as informal caregivers of people with dementia. The perspectives of people with dementia were represented by the Dutch Alzheimer's Society, which also participated in the consortium of organisations that monitored the study. Consortium partners were updated about the preliminary results of the study during regular meetings. The Dutch Alzheimer's Society helped recruit patients for this study. The study participants were updated about the results through regular news letters.

\section{RESULTS}

\section{Respondent characteristics}

Twenty-five of the 30 care networks we contacted and agreed to participate. The reason given by the five who declined to participate was caregiver burden. We excluded two care networks: one because the person with dementia was unable to participate in the interview at that time and the other because the diagnosis had been reset to mild cognitive impairment during the study. Our total study consisted of 23 care networks. This paper focuses on the 19 care networks in the study that discussed the issue of daycare in the interviews. Table 1 provides an overview of the characteristics of those 19 care networks with their original identification number. For an overview of all care networks, see Groen-van de Ven et $a l^{25}$ Two of 19 care networks had only one informal caregiver each who could be interviewed, which left 93 respondents altogether for the analysis of this paper. The professional caregivers involved included case managers, home care nurses, daycare employees and a psychotherapist. Two care networks opted out after the first interview round because of the burden of the study. We have used the information from the first interview rounds for these networks. One or more interviews in nine of the care networks could not be conducted during the second or third round because of circumstances such as holidays, moving house or a change of the professionals involved. In total, we used

Table 1 Characteristics of the participants in the care networks

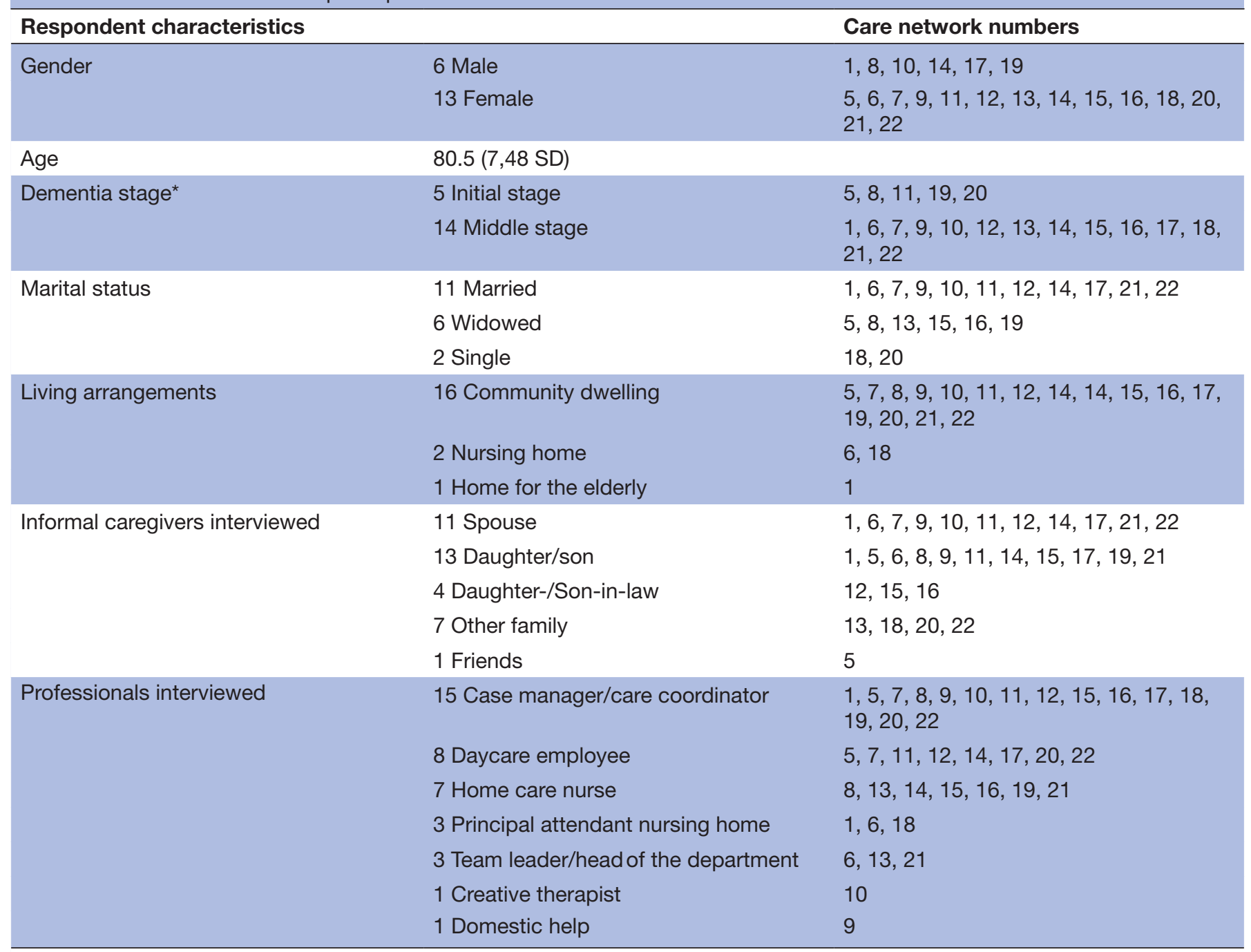

*The stage of the dementia was based on the professional expertise of the case manager or other professional interviewed. 
Table 2 Themes, categories and codes for participation in decision making about daycare

\begin{tabular}{|c|c|c|}
\hline Themes & Categories & Codes \\
\hline \multirow[t]{5}{*}{ Initial expectations about daycare } & \multirow[t]{2}{*}{ Initiating decision making about daycare } & Anticipating \\
\hline & & Taking initiatives \\
\hline & Positive expectations about daycare & Preferences for daycare \\
\hline & \multirow[t]{2}{*}{ Negative expectations about daycare } & Negative associations with daycare \\
\hline & & Dislike of daycare \\
\hline \multirow[t]{10}{*}{ Negotiating about trying daycare } & \multirow{3}{*}{$\begin{array}{l}\text { Participating in conversations about } \\
\text { daycare }\end{array}$} & Conversations about daycare \\
\hline & & $\begin{array}{l}\text { Contributing to discussions about } \\
\text { daycare }\end{array}$ \\
\hline & & Informing oneself about daycare \\
\hline & Promoting daycare & Repeatedly discussing daycare \\
\hline & \multirow[t]{3}{*}{ Resisting daycare } & Rejecting daycare \\
\hline & & Being ambivalent about daycare \\
\hline & & Postponing daycare \\
\hline & \multirow[t]{3}{*}{ Attuning to others } & Listening to others \\
\hline & & Attuning to the person with dementia \\
\hline & & Weighing different perspectives \\
\hline \multirow[t]{5}{*}{ Trying daycare } & Working together to try out daycare & Resigning \\
\hline & \multirow{2}{*}{$\begin{array}{l}\text { Negative reactions of people with } \\
\text { dementia toward daycare }\end{array}$} & Negative experiences \\
\hline & & Negative behaviour \\
\hline & \multirow[t]{2}{*}{ Deciding about daycare } & Determining \\
\hline & & Arranging daycare \\
\hline
\end{tabular}

244 interviews in the analysis. We reached the intended variation in our sample with respect to gender, stage of dementia and type of informal caregivers. However, we reached mainly people with dementia with a midlevel socioeconomic status, and we reached only a few with low or high socioeconomic status. We did reach data saturation regarding our study topic, since the last interviews did not provide new codes and themes. ${ }^{37}$

\section{Results for objective 1: themes related to taking part in decision making about daycare}

We found three themes regarding participation in this decision making: (1) initial expectations of daycare, (2) negotiating about trying daycare and (3) trying daycare. Table 2 describes the themes with the related categories and codes on which they are based.
Theme 1: initial expectations of daycare

This theme includes care network members starting to discuss and consider daycare for the person with dementia. The categories in this theme are (1) initiating decision making, (2) positive expectations and (3) negative expectations. The care network members' initial expectations of daycare are critical for continuing the decision making because they have an impact on how the negotiation about trying daycare proceeds.

\section{Initiating decision making about daycare}

Decision making about daycare was initiated when one of the care network members started an exchange about the idea of daycare with one or more other care network members. It is notable that people with dementia and their spouses were not the ones to initiate conversations 
about daycare. Adult children were often the ones who initiated the conversations. They wanted to prevent overburdening of the spouse.

I did raise the issue with my mother before: Wouldn't it be good for him to go to the daycare centre so that you can catch your breath. - Daughter of a man with dementia, care network 1

The professionals also initiated discussions with couples about daycare. When no spouse was present, the adult children (or other relatives) and the professionals initiated discussions about daycare.

The daycare is a result of the daughters-in-law telling us that there was 1 day in the week when actually no one came by and then he used to call sometimes to say that he was feeling alone, and then they thought: Well, we might try daycare. Well, I suggested that and discuss it with them. - Case manager of a woman with dementia living alone, care network 16

\section{Positive expectations of daycare}

Children and other relatives, as well as healthcare professionals, were in favour of daycare for the person with dementia. The only exception to this is care network 8 where the daughter had positive expectations toward daycare, but the son followed the negative expectations of his father. The people with dementia and their spouses were the participants who did not always have positive expectations of daycare. Positive ideas and expectations about daycare related to concerns about the deterioration of the person with dementia, well-being issues such as loneliness of the person with dementia, caregiver burden and conflicts between spouses that made daycare necessary.

We talked about daycare, partly because the spouse mentioned he couldn't cope at home with his wife. Because of the tensions between them. And partly it was because we thought: This woman should have something to do now and then, she just sits there at home. Well, and that combination, it just adds up to, that means daycare. - Case manager of a woman with dementia, care network 11

\section{Negative expectations of daycare}

The people with dementia and their spouses sometimes had negative ideas and expectations of daycare. They related to the idea that the person with dementia was not yet affected enough to need daycare; that daycare would not be useful or suitable, possibly because the person with dementia did not like being in groups; and that daycare would limit the autonomy of the person with dementia. Negative feelings associated with daycare included: mistrust; being or feeling abandoned; fear, anger, grief and shame due to loss of functioning; and guilt about putting someone away.
I think she is far too good to go to daycare, then she would rapidly worsen. Because then she wouldn't be activated anymore. And now her brother comes by for a walk with her, or he drops in once in a while, or people come over for me, or she will go along with me, just for companionship. Well, it's out of necessity, she goes along to a meeting or something with me. - Spouse of a woman with dementia, care network 22

\section{Theme 2: Negotiating about trying daycare}

This theme involves care network members working toward getting the person with dementia to try daycare. The theme includes (1) participating in conversations about daycare, (2) promoting daycare, (3) resisting daycare and (4) attuning to others. The negotiation about trying daycare forms a critical point in the decision-making process. Depending on how the negotiation proceeded, the person with dementia might or might not move toward trying daycare.

\section{Participating in conversations about daycare}

Conversations about daycare occurred at different times and places, as well as in different forms, such as face to face, by phone or e-mail. The interviews from different rounds showed that the issue was often discussed multiple times before a decision was reached. In four care networks, the person with dementia was deliberately not involved in some of these conversations. Openly discussing daycare was seen as too confronting, or care network members were afraid that it would result in resistance of the person with dementia to daycare.

(The woman with dementia) is not present herself at this meeting of course. Because you want to protect your client. Because matters may come up that the client doesn't judge the same way. You discuss the more heated issues, so to speak. The results will be submitted to her afterwards, because she has to be up to date at a certain point about the changes that are going to come. - Daycare employee of a woman with dementia, care network 22

In most situations, the conversations focused on whether or not daycare was acceptable, without carefully exploring the alternatives. Only in four care networks alternatives to daycare were discussed because the person with dementia was not willing to try daycare. The available or perceived options for daycare were seen as limited by these care networks, especially because the options included mainly group activities.

\section{Promoting daycare}

Care network members in favour tried to promote daycare to the person with dementia and the spouse by encouraging them to try it. They did this by talking positively about daycare, adjusting their phrasing to what was acceptable to the person with dementia, repeatedly proposing the issue and looking for support from other 
care network members who had an influence on the person with dementia.

The doctor did encourage me to go to the daycare here. And, I must say, up until now it has turned out to be better than expected. - Woman with dementia, care network 5

Well, it wasn't during the first consultation, that she said: 'Yes, that daycare, that's what we'll do'. Before that, it was more like [Let's] think about it a little more. I think that after two or three consultations she gave her approval to arrange the daycare. - Case manager of a woman with dementia, care network 11

\section{Resisting daycare}

People with dementia and the spouses too in some cases tended to resist the efforts of others to get them to try daycare. They did this by rejecting daycare and by protesting or showing negative emotions when daycare was discussed. Another way of resisting included expressing doubts about daycare. The people with dementia and their spouses would also resist daycare by postponing or delaying discussions about it. In several care networks, reaching a decision about daycare was postponed, and the issue came up in different interview rounds.

You really feel a bit pushed aside, you know, in the beginning. That made me fight in the beginning. I didn't want that. - Woman with dementia, care network 11

We decided that we would visit a care farm, one that I had already seen before. She said that she agreed. But well, she finds excuses not to go every time. - Spouse of a woman with dementia, care network 9

\section{Attuning to others}

Attuning was necessary for reaching common ground, given the different perspectives and interests of the participants. Attuning included listening to the ideas and advice of others and weighing different perspectives. The people with dementia tended to stick to their own standpoints, with other care network members attuning to their preferences. A commonly used phrase was, 'You cannot force someone to accept daycare.' Children were more likely to go against the wishes of the person with dementia; however, those with decision-making responsibilities for a parent living alone were cautious about overruling the person with dementia. Attuning is illustrated by the following quotation, where the activity coach had a different point of view than the informal caregiver, but tried to attune to her point of view.

The spouse indeed really puts (the person with dementia) in the centre. I believe she talks about things with (the person with dementia), how she sees them. With daycare too. She asked whether (the person with dementia) really wanted to go there. Rightly of course. I mean, as long as it's possible it is very important that the client is the first one to express what she wants. - Activity coach of a woman with dementia, care network 22

\section{Theme 3: trying daycare}

This theme is about people with dementia trying and experiencing daycare as part of reaching a decision about it. It includes the categories of (1) working together to try daycare, (2) positive reactions of people with dementia to daycare, (3) negative reactions of people with dementia to daycare and (4) deciding about daycare. Trying daycare is a critical point in the decision making because continuing or discontinuing daycare depends on the reactions of the person with dementia. Therefore, this is another phase in the decision making where people with dementia have an important say.

\section{Working together to try daycare}

Arranging a tryout was often still part of the process of encouraging the person with dementia to use daycare. Their children and home care nurses were eager to make the tryout as easy as possible so that the person with dementia would not hesitate. They did this by visiting the daycare centre together, bringing the person to the daycare or making sure that the person was ready to go when the bus to the daycare arrived. In this way, the transport of people with dementia to the daycare facility was a practical solution and part of encouragement to use daycare.

The first days that she went there (to the daycare centre) I tried to take time for her. That I would be there to help her shower and dress and to stay until the taxi arrived. And after a few days she actually thought it was great (to go there). - Home care nurse of a woman with dementia, care network 12

A tryout took place once the person with dementia had consented to it. Only in cases where there was risk of overburdening and the spouses had started to relinquish some of their care would the person with dementia perhaps be forced to try daycare.

My mother-in-law always said: I won't go to daycare'. But well, there comes a time when they can no longer make that kind of decision themselves. At least, the care became too burdensome for my father-in-law. - Daughter-in-law of a woman with dementia, care network 12

\section{Positive reactions of people with dementia to daycare}

For care network members, the person with dementia's reactions to daycare, once he or she had tried it out, were very important. Positive reactions included positive experiences, such as liking daycare or enjoying the activities; positive feelings, such as relief, happiness and trust; and positive behaviour toward daycare.

She goes with pleasure (to daycare). She makes sure that she is downstairs on time. This morning I 
overslept a bit. Well, she had everything all ready. She had set the table, because 'Yes, I have to be on time'. - Spouse of a woman with dementia, care network 22

When people with dementia reacted positively to daycare, it helped the spouse and children decide about daycare. Positive reactions reinforce the decision about daycare. Furthermore, informal caregivers showed reactions based on their own experiences with the person with dementia visiting daycare. Positive reactions of informal caregivers related to feelings of relief and having a sense of control of the situation.

\section{Negative reactions of people with dementia to daycare}

Negative reactions to daycare included negative experiences, such as disliking daycare or being dissatisfied, and negative behaviour such as complaining, not participating in the activities or walking away. Care network members took negative reactions seriously. Daycare would be stopped or discussions about reducing daycare would be initiated.

It seems as if he enjoys it all, only if you speak to him about it, he says: 'What am I doing here? Why am I here? Why can't I be with my wife?' I do take that back to the care coordinator every time. In the sense of, 'Can we do something about that? We discussed the idea of him staying home 1 day a week. - Principal attendant of man with dementia, care network 1

However, care network members also found it important to give time to the person with dementia to adjust to daycare, as the reactions of people with dementia about daycare might shift over time from negative to positive.

We warned her (laughs). Try it first. If you don't feel like going, you quit. So, just try, because, if you really think it's terrible, all right, then no! We'll quit. Well, it took several months before she found her niche. Daughter of a woman with dementia, care network 11

Sometimes negative reactions were overruled by informal caregivers who were overburdened.

[Interviewer: Did she consent to extend the daycare to 3 days a week?] Well, not really consent. She was against it until the day it started. She didn't want to go another day. But, well, in the end, you can't really do anything else. Because the care becomes too much. Daughter-in-law of a woman with dementia, care network 12

\section{Deciding about daycare}

Once daycare had been tried, the care network members explicitly or implicitly reached a decision. The reactions of the person with dementia were important cues for the informal caregivers and professionals involved in reaching this decision.

She signed her care plan last week and she has said that she feels comfortable here and that she enjoys coming here. And I believe that. Sometimes you see that clients say one thing here and at home it's a different story. That they are not motivated at all. But, with her, I think she is really motivated and enjoys coming here. - Daycare employee of a woman with dementia, care network 5

Meanwhile, she went to the daycare, but she didn't like it because everyone was asleep according to her. (Both the interviewer and respondent laughed). She was like: 'That dead place, I don't fancy that'. So, well, she made the choice herself. We showed her what it was like, she has been there twice, and the third time she was like: 'I won't go there anymore'. That was her choice, and there must have been someone trying to convince her otherwise, but no was no. - Case manager of a woman with dementia, care network 16

The whole process of deciding about daycare could start over once the situation of the person with dementia changed because of a decline in functioning or when the informal caregiver relinquished care. Follow-up decisions included extending or reducing daycare and changing between groups.

\section{Results objective 2: types of participation trajectories}

The themes and categories elicited for objective one functioned as the dimensions and properties for constructing our typology. Table 3 displays them. We distinguished three different types of participation trajectories on the basis of the manifestation of the dimensions and properties in our care networks: (1) working together positively toward daycare, (2) bringing conflicting perspectives together to facilitate trying daycare and (3) not reaching a commitment to try daycare. Table 4 displays the different types of participation trajectories.

\section{Type 1: working together positively toward daycare}

This type of participation trajectory consists of situations that were characterised by congruent positive expectations about daycare within the care network. There was no resistance to the idea of trying daycare in these situations, and once it has been tried out, the person with dementia and the informal caregivers experienced the daycare as positive. In these situations, the decision to reach daycare was easy, and things were promptly arranged without much discussion.

It all went very fast...that she could go there (to the daycare). And, at first she said: 'I'll just try it first, and then we'll see.' But, she found it terrific from the first day. - Daughter of a woman with dementia, care network 5

Type 2: bringing conflicting perspectives together toward trying daycare

This trajectory type is characterised by conflicting perspectives of the care network members about 
Table 3 Criteria for the construction of the types of participation trajectories

\begin{tabular}{|c|c|c|}
\hline Dimensions (themes) & Properties (categories) & $\begin{array}{l}\text { Manifestations of the properties in the care } \\
\text { networks }\end{array}$ \\
\hline \multirow{2}{*}{$\begin{array}{l}\text { Initial expectations toward daycare } \\
\text { (theme 1) }\end{array}$} & Positive (category 1.2) & All care network members positive \\
\hline & Negative (category 1.3) & Conflicting perspectives of participants* \\
\hline \multirow[t]{2}{*}{ Negotiation about daycare (theme 2) } & Promoting daycare (category 2.2) & Promoting dominant, no resistance \\
\hline & Resisting daycare (category 2.3) & $\begin{array}{l}\text { Resisting dominant, promoting participants } \\
\text { attuning to the resisting participants }\end{array}$ \\
\hline \multirow[t]{2}{*}{ Try-out of daycare (theme 3) } & Yes (category 3.1) & Yes \\
\hline & No (category 3.1) & No \\
\hline \multirow[t]{2}{*}{ Experiences with daycare (theme 3) } & Positive experiences (category 3.2) & Positive experiences \\
\hline & Negative experiences (category 3.3) & Negative experiences \\
\hline
\end{tabular}

${ }^{*}$ Purely negative expectations are never seen, since the initiator of the decision making about daycare has positive expectations.

trying daycare. The person with dementia and some of the spouses are negative about trying it, whereas other care network members are positive. Sometimes there are multiple conversations or attempts to take the person with dementia to try daycare. Care network members take the time to think things over as long as they feel this is safe for the person with dementia and doable for the informal caregivers.

Table 4 Types of participation trajectories of the decision making about daycare

\begin{tabular}{|c|c|c|c|c|c|}
\hline Trajectory type & Initial expectations & Negotiation about daycare & $\begin{array}{l}\text { Tryout of } \\
\text { daycare }\end{array}$ & $\begin{array}{l}\text { Experiences } \\
\text { with daycare }\end{array}$ & $\begin{array}{l}\text { Care } \\
\text { networks } \\
\text { within this } \\
\text { trajectory }\end{array}$ \\
\hline $\begin{array}{l}\text { 1. Working together } \\
\text { positively toward } \\
\text { daycare }\end{array}$ & $\begin{array}{l}\text { All participants have } \\
\text { positive expectations }\end{array}$ & Promoting daycare & yes & $\begin{array}{l}\text { Positive about } \\
\text { daycare }\end{array}$ & $5,7,13,17$ \\
\hline $\begin{array}{l}\text { 3. No commitment } \\
\text { to try daycare }\end{array}$ & $\begin{array}{l}\text { Person with dementia } \\
\text { negative, the informal } \\
\text { caregivers are negative } \\
\text { or have no clear } \\
\text { expectations about } \\
\text { daycare, professionals } \\
\text { are positive }\end{array}$ & $\begin{array}{l}\text { The professionals in these situations } \\
\text { promote daycare, while the person } \\
\text { with dementia resists. The informal } \\
\text { caregivers either resist as well or } \\
\text { align with the person with dementia. } \\
\text { Daycare does not suit the person with } \\
\text { dementia because he or she dislikes } \\
\text { groups or does not like being away } \\
\text { from home. Professionals eventually } \\
\text { accept that the person with dementia } \\
\text { does not want to try daycare }\end{array}$ & No & & 10,15 \\
\hline
\end{tabular}


The way he is now, he is not wandering or anything, you know? I think he's very lonely, but he says he is doing fine. I ask him all the time: How are you doing? Don't you want more?' Then he says: No, I'm fine. Well, then I may feel he is lonely, and think he needs more activities, but if he keeps saying he doesn't want that then, you have to let it go. I had difficulties with that at first. But, my husband says it too: Let it go. You can't force it. - Daughter of a man with dementia, care network 8

It is notable that the professionals seldom discussed alternatives to daycare. Therefore, the choice was either accepting or not accepting daycare. Continuing daycare after the tryout depends on the reactions to daycare of the person with dementia. Positive and mixed experiences lead to a continuation of daycare, whereas negative experiences imply that daycare stops.

And wonder of wonders, she began to like it (daycare), and gradually she recovered physically, which made her a lot clearer. You could see that. She was more approachable. She became a totally different female. - Case manager of a woman with dementia, care network 11

Daycare is something she absolutely does not want. We even went to the daycare one afternoon with her and she experienced it all. But, she definitely does not want it. - Team leader for nurses of the home care organisation of a woman with dementia, care network 21

\section{Type 3: not reaching a commitment to try daycare}

This type of participation trajectory is characterised by the person with dementia being part of a small network and resisting daycare. The secondary informal caregivers in these care networks did not have a clear role in the decision making. The primary informal caregivers were either negative or had no clear role. The initiative for discussing daycare came from the professionals. They tended to have multiple conversations about daycare in which they tried to encourage the person with dementia and primary informal caregiver to try daycare. However, these discussions did not lead to trying daycare. Then, finally, the professionals accepted the fact that daycare was not suitable in this situation. The professionals did not discuss alternatives to daycare, even if the informal caregivers came up with alternatives themselves. These care networks decided to manage the situation as best as they could, without daycare.

In the past I tried to guide her to a form of daycare. Because then she wouldn't have to have this private care, because she would be taken care of for a few hours. She could get a meal there, she could go to the hairdresser and the physiotherapy. But, she wouldn't go outside for all the tea in China. So, at a given moment, you reconcile to the situation, and you accept that. - Case manager of a woman with dementia, care network 15 .

They (community services) keep suggesting that he should first try daycare in a group. That he should undergo daycare here at (name of a nursing home). Well, the misery is that he doesn't hear anything in a great hall full of people like that. And then the sort of things they do there. Old Dutch activities, that's wasted on him. I mean, he is a musician with absolute pitch. That singing with all those different voices hurts his ears. [...] And, he doesn't stand up for himself in groups. He gets more depressed and at home he complains. But, then they said to me, You can just try it for a month and if it doesn't work, he will get another indication [for one-to-one care]. I said: So, he and I must be worn out for a month? It's pure fraud. You know in advance he can't do it. I refuse to lie about it. - Spouse of a man with dementia, care network 10.

\section{DISCUSSION}

We explored how people with dementia and their informal and professional caregivers participate in decision making about daycare. Three themes representing the critical points of the participation in the decision making about daycare emerged: (1) the initial positive or negative expectations of daycare; (2) negotiating about trying daycare by promoting, resisting or attuning to others; and (3) trying daycare, resulting in positive or negative reactions from people with dementia, and leading to a decision about daycare. The ways in which care networks proceeded through these three critical points resulted in a typology of participation trajectories, including (1) working positively together toward daycare, (2) bringing conflicting perspectives together toward trying daycare and (3) not reaching commitment to try daycare.

\section{Implications for practice and theory}

Taken together, the results of our study make several important contributions to the current theory and understanding of the practice of shared decision making. We believe four elements should be incorporated in a theoretical model of shared decision making for people with dementia: (1) shared decision making in dementia should aim at moving from initial to experienced preferences, (2) non-verbal contributions should be acknowledged as factors in the decision making along with the verbal expressions of people with dementia, (3) the important roles of both primary and secondary informal caregivers need to be acknowledged as both are important for reaching necessary compromises and (4) professionals should work together with people with dementia and their informal caregivers to find tailor-made alternatives to daycare if necessary. We explain each of these elements in the following paragraphs.

First, the findings demonstrate that a tryout period is an essential element of the decision making for people with 
dementia. For people with dementia, it is often quite difficult to forecast their preferences on the basis of factual information about options. ${ }^{19}$ Our results show that initial preferences based on information alone may change when people with dementia experience daycare. A tryout period is important for them so that they can experience daycare without having to decide whether they want to continue it. ${ }^{13}$ Whereas shared decision making in general aims at moving from initial preferences to informed preferences, professionals should focus more at moving from initial preferences to experienced preferences for people with dementia.

Second, the findings suggest that people with dementia exercise considerable influence with their preferences and reactions to daycare. During the three critical points of the decision making about daycare, they provide arguments and standpoints about daycare that are taken seriously by the other participants. They stand for their preferences and are not easily persuaded to act contrary to those preferences. In addition to their verbal expressions about daycare, the people with dementia's emotions and behaviours during the daycare tryout serve as important cues for their preferences. ${ }^{30}$ In this way, they influence the decision-making pace as well as the direction of the decision. This is in line with Boyle's findings ${ }^{38}$ that people with dementia who lack deliberative capacity exercise agency in other non-verbal ways. Focusing solely on the cognitive contributions to decision making ignores the other contributions of the person with dementia and does not fit in with the ways in which the various participants mutually influence each other. Professionals who want to facilitate shared decision making with people need to acknowledge the non-verbal contributions of emotions and reactions as factors in decision making.

Third, the types of decision trajectories show the important role of informal caregivers in bringing together conflicting perspectives. The various participants have distinct perspectives, so that reaching a decision about daycare means negotiating these different points of view by promoting and resisting daycare and by attuning to each other's views. Adult children or professionals are the ones who initiate decision making about daycare. People with dementia and sometimes their spouses as well tend to start off with negative expectations of daycare. They resist daycare. Their children are often more positive from the beginning and tend to promote daycare. Their perspectives are more in line with those of the professionals involved. This is in line with the work of Clemmensen $e t a l^{39}$ who found differences between the 'protective relative' and the 'decisive relative'. The protective relative usually lives with the person with dementia and tends to protect the relationship with the person, conceal carer burden and resist change. The decisive relative tends to initiate decision making, articulate the problems and address the carer burden of the protective relative. Our results seem to indicate that including the perspectives of carers with a decisive role may be crucial in initiating decision making and in reaching compromises.
Only $20 \%$ of shared decision-making models recognise informal caregivers as relevant participants for shared decision making. ${ }^{40}$ Their roles are often incorporated in the patient role without explicating their specific contributions to the decision making. An exception to this is the interprofessional shared decision-making model of Légaré et al. ${ }^{41}$ Our study exemplifies that the perspectives of informal caregivers are different from those of the patient and that the perspectives of the different informal caregivers involved also vary.

Fourth, our results indicate that the decision about daycare is often presented as a yes-or-no decision by professionals. Alternatives to daycare are seldom discussed. This is especially troublesome for those people with dementia who dislike groups or who do not prefer the activities at the daycare centre. Since daycare is aimed at the person with dementia and at relieving caregiver burden, ${ }^{2}{ }^{5}$ it seems important to at least consider alternative options. Such options may not be readily available. In complex situations such as the ones dementia creates, shared decision making requires professionals to engage in conversations with their patients that go beyond merely informing them about the options they know of. Rather, they should have open conversations with people with dementia and their informal caregivers that allow all the participants to consider new information, perspectives and options. ${ }^{13} 42$ This might result in 'third ways' that the professional had not yet thought about. The difficulty is that professionals may have their own interests in the daycare decision as well, on the basis of the organisation of the healthcare in their region. ${ }^{43}$ This might be part of the reason why professionals do not always take the alternatives into consideration as presented by the informal caregivers in the care networks that did not reach a commitment for trying daycare.

\section{Strengths and limitations}

This is the first study to explore the participation of different participants in the decision making about daycare in dementia. The decision about daycare is an important one, since it often marks the point in time from which people with dementia engage in professionals care on a regular basis. Our study includes the perspectives of people with dementia, their informal caregivers and the professionals involved. As such, it provides rich stories about participation in the decision making regarding daycare. $^{32}$ The perspectives of people with dementia themselves are often neglected in research. ${ }^{35}$

This study also has several limitations. There were various interviewers, some of whom were undergraduate students. This may have led to variation in the quality of the interview data between interview rounds. All the interviewers were trained and received feedback on their interview style after each interview, but there were still differences in the extent to which they persisted in asking questions. To minimise the effect of different interviewers, we made sure that the interviews of each care network in a given interview round were conducted by one interviewer. 
This study involves people with dementia who were able to participate in an interview and who had informal caregivers present. Cases in which the person with dementia cannot communicate and cases in without informal caregivers could likely present different or additional experiences. Our findings are limited by the fact that they represent the Dutch context and focus at shared decision making about daycare. However, we believe that our findings may be transferable to shared decision making for people with dementia outside the Netherlands and for other decision topics. However, certain elements should be taken into account to assure that the situation is similar to our context. ${ }^{44}$ These include (1) people with dementia are seen as partners in the decision making, (2) informal caregivers are involved in the decision making and (2) it is possible to try out options before reaching a decision.

\section{Future directions}

Our results contribute to the social health of people with dementia by appreciating their potential to participate in decision making and by acknowledging the roles of informal caregivers for people with dementia to manage their own lives. ${ }^{45}$ Future research could strengthen these insights by exploring how the remaining capacities of people with dementia with respect to decision making can effectively be included in the decision making. Besides this, our study excluded the perspectives of people with dementia without informal caregivers. Research about shared decision making for people with dementia who lack the support of informal carers could reveal how they reach decisions together with their professionals, thereby contributing to their social health.

(1) the capacity to fulfil one's potential and obligations, (2) the ability to manage one's life with some degree of independence despite a disease, and (3) the ability to participate in social activities. Social

\section{CONCLUSION}

Our results show that shared decision making with people with dementia is possible and requires an adapted process of decision making. The attention should shift from merely deliberating about daycare to trying it in order to move from initial expectations of daycare to experienced preferences. Doing this allows people with dementia to have an impact on the decision making. The other participants usually honour the preferences based on experiences with daycare. While shared decision making in general aims at moving from initial preferences to informed preferences, professionals should focus more on moving from initial preferences to experienced preferences for people with dementia.

Acknowledgements We would like to thank all the study participants for the time invested in the study and for sharing their personal stories with us.
Contributors LG is a PhD candidate and the principal investigator of the project. She developed the research questions and methods of this study under the guidance of her supervisors. She conducted part of the interviews and analysed all data. She made the first draft for the paper and processed the feedback of the coauthors into subsequent versions, leading to the final version. CS is the supervisor of LG. She was involved in developing the research question and methods, she gave feedback on the analysis and the interim results presented by $L G$ and $F d G$, and she gave feedback to $L G$ about all drafts of the article. FdG is co-researcher on the project. She took part in developing the methods and in the analysis of the data. She commented on several versions of the article. MS conducted part of the interviews and gave feedback about several drafts of the article. JE is supervisor of $L G$. He was involved in developing the research question and methods, he gave feedback on the analysis and the interim results presented by $L G$ and FdG, and he gave feedback to $L G$ about several drafts of the article. JJ is supervisor of LG. He was involved in developing the research question and methods, he gave feedback on the analysis and the interim results presented by $L G$ and FdG, and he gave feedback to $L G$ about all drafts of the article. MV is supervisor and promoter of LG. She was involved in developing the research question and methods, she gave feedback on the analysis and the interim results presented by $L G$ and FdG, and she gave feedback to $L G$ about all drafts of the article.

Funding This work was supported by the Regional Attention and Action for Knowledge Circulation (RAAK) program of the Foundation Innovation Alliance (SIAStichting Innovatie Alliantie) with funding from the Ministry of Education, Culture, and Science, grant number PR0-1-014.

Competing interests None declared.

Ethics approval Ethical board of the Isala Clinics in Zwolle (number 10.11113).

Provenance and peer review Not commissioned; externally peer reviewed.

Data sharing statement Extra data (interview texts) are available by emailing Leontine Groen - van de Ven: Im.groen-vande.ven@windesheim.nl.

Open Access This is an Open Access article distributed in accordance with the Creative Commons Attribution Non Commercial (CC BY-NC 4.0) license, which permits others to distribute, remix, adapt, build upon this work non-commercially, and license their derivative works on different terms, provided the original work is properly cited and the use is non-commercial. See: http://creativecommons.org/ licenses/by-nc/4.0/

(c) Article author(s) (or their employer(s) unless otherwise stated in the text of the article) 2017. All rights reserved. No commercial use is permitted unless otherwise expressly granted.

\section{REFERENCES}

1. Brataas HV, Bjugan $\mathrm{H}$, Wille $\mathrm{T}$, et al. Experiences of day care and collaboration among people with mild dementia. $J$ Clin Nurs 2010;19:2839-48.

2. Robinson A, Lea $E$, Hemmings L, et al. Seeking respite: issues around the use of day respite care for the carers of people with dementia. Ageing Soc 2012;32:196-218.

3. Contador I, Fernández-Calvo B, Palenzuela DL, et al. A controlbased multidimensional approach to the role of optimism in the use of dementia day care services. Am J Alzheimers Dis Other Demen 2015;30:686-93.

4. de Jong JD, Boersma F. Dutch psychogeriatric day-care centers: a qualitative study of the needs and wishes of carers. Int Psychogeriatr 2009;21:268-77.

5. Mavall L, Malmberg B. Day care for persons with dementia: an alternative for whom? Dementia 2007;6:27-43.

6. Menne HL, Tucke SS, Whitlatch CJ, et al. Decision-making involvement scale for individuals with dementia and family caregivers. Am J Alzheimers Dis Other Demen 2008;23:23-9.

7. Fetherstonhaugh D, Tarzia L, Nay R. Being central to decision making means I am still here!: the essence of decision making for people with dementia. J Aging Stud 2013;27:143-50.

8. Elwyn G, Frosch D, Thomson R, et al. Shared decision making: a model for clinical practice. J Gen Intern Med 2012;27:1361-7.

9. Stiggelbout AM, Van der Weijden T, De Wit MP, et al. Shared decision making: really putting patients at the centre of healthcare. BMJ 2012;344:e256.

10. Elwyn G, Edwards A, Gwyn R, et al. Towards a feasible model for shared decision making: focus group study with general practice registrars. BMJ 1999;319:753-6.

11. Miller LM, Whitlatch CJ, Lyons KS. Shared decision-making in dementia: a review of patient and family carer involvement. Dementia 2016;15:1141-57. 
12. Wolfs CA, de Vugt ME, Verkaaik M, et al. Rational decision-making about treatment and care in dementia: a contradiction in terms? Patient Educ Couns 2012;87:43-8.

13. Epstein RM, Gramling RE. What is shared in shared decision making? Complex decisions when the evidence is unclear. Med Care Res Rev 2013;70:94S-112.

14. Groen-van de Ven L, Smits C, Span M, et al. The challenges of shared decision making in dementia care networks. Int Psychogeriatr 2016;9:1-15

15. Moye J, Marson DC. Assessment of decision-making capacity in older adults: an emerging area of practice and research. $J$ Gerontol $B$ Psychol Sci Soc Sci 2007;62:P3-P11.

16. Feinberg LF, Whitlatch CJ. Are persons with cognitive impairment able to state consistent choices? Gerontologist 2001;41:374-82.

17. Whitlatch $\mathrm{C}$, Menne $\mathrm{H}$. Don't forget about me! Decision-making by people with dementia. American Society on Aging 2009;33:66-74.

18. Karel MJ, Gurrera RJ, Hicken B, et al. Reasoning in the capacity to make medical decisions: the consideration of values. J Clin Ethics 2010;21:58-71.

19. Entwistle VA, Watt IS. Patient involvement in treatment decisionmaking: the case for a broader conceptual framework. Patient Educ Couns 2006;63:268-78.

20. Entwistle VA, Carter SM, Cribb A, et al. Supporting patient autonomy: the importance of clinician-patient relationships. J Gen Intern Med 2010;25:741-5.

21. Epstein RM. Whole mind and shared mind in clinical decisionmaking. Patient Educ Couns 2013;90:200-6.

22. Boyle G. 'She's usually quicker than the calculator': financial management and decision-making in couples living with dementia. Health Soc Care Community 2013;21:554-62.

23. Smebye KL, Kirkevold M, Engedal K. How do persons with dementia participate in decision making related to health and daily care? a multi-case study. BMC Health Serv Res 2012;12:241.

24. Hamann J, Bronner K, Margull J, et al. Patient participation in medical and social decisions in Alzheimer's disease. J Am Geriatr Soc 2011;59:2045-52.

25. Groen-van de Ven L, Smits C, Oldewarris K, et al. Decision trajectories in dementia care networks: decisions and related key events. Res Aging 2017;39:1039-71.

26. Coyne IT. Sampling in qualitative research. purposeful and theoretical sampling; merging or clear boundaries? J Adv Nurs 1997;26:623-30.

27. Creswell J. Qualitative inquiry and research design: choosing among five traditions. Thousand Oaks: Sage, 1998.

28. Nygård L. How can we get access to the experiences of people with dementia? Scand J Occup Ther 2006;13:101-12.
29. Elo S, Kyngäs $\mathrm{H}$. The qualitative content analysis process. J Adv Nurs 2008;62:107-15.

30. Kluge S. Empirically grounded construction of types and typologies in qualitative social research. Forum: qualitative social research 2000;1. Art. 14 http://www.qualitative-research.net/index.php/fqs/ article/viewArticle/1124/2499.

31. Corbin JM, Strauss A. Grounded theory research: procedures, canons, and evaluative criteria. Qual Sociol 1990;13:3-21.

32. Kendall M, Murray SA, Carduff E, et al. Use of multiperspective qualitative interviews to understand patients' and carers' beliefs, experiences, and needs. BMJ 2009;339:b4122.

33. Murray SA, Kendall M, Carduff E, et al. Use of serial qualitative interviews to understand patients' evolving experiences and needs. BMJ 2009;339:b3702.

34. Boeije H. A purposeful approach to the constant comparative method in the analysis of qualitative interviews. Quality and Quantity 2002;36:391-409.

35. Murphy K, Jordan F, Hunter A, et al. Articulating the strategies for maximising the inclusion of people with dementia in qualitative research studies. Dementia 2015;14:800-24.

36. Meulenbroek O, Vernooij-Dassen M, Kessels RPC, et al. Informed consent in dementia research. Legislation, theoretical concepts and how to assess capacity to consent. Eur Geriatr Med 2010;1:58-63.

37. Fusch PI, Ness LR. Are we there yet? Data saturation in qualitative research. The qualitative report 2015;20:1408-16.

38. Boyle G. Recognising the agency of people with dementia. Disabil Soc 2014;29:1130-44.

39. Clemmensen TH, Busted LM, Soborg J, et al. The familys experience and perception of phases and roles in the progression of dementia: an explorative, interview-based study. Dementia 2016:1-24.

40. Stacey D, Légaré F, Pouliot S, et al. Shared decision making models to inform an interprofessional perspective on decision making: a theory analysis. Patient Educ Couns 2010;80:164-72.

41. Légaré F, Stacey D, Brière N, et al. An interprofessional approach to shared decision making: an exploratory case study with family caregivers of one IP home care team. BMC Geriatr 2014;14:83.

42. Epstein RM, Street RL. Communication shared mind: decision making, and autonomy in serious illness. Ann Fam Med 2011;9:454-61.

43. St-Amant O, Ward-Griffin C, DeForge RT, et al. Making care decisions in home-based dementia care: why context matters. Can J Aging 2012;31:423-34.

44. Krefting L. Rigor in qualitative research: the assessment of trustworthiness. Am J Occup Ther 1991;45:214-22.

45. Vernooij-Dassen M, Jeon YH. Social health and dementia: the power of human capabilities. Int Psychogeriatr 2016;28:701-3. 